\title{
O IMPACTO NEGATIVO DAS 'FAKENEWS' NOS SERVIÇOS PÚBLICOS DE SAÚDE: REDUÇÃO DA VACINAÇÃ̃O E DA ERRADICAÇÃO DE DOENÇAS NO BRASIL
}

\author{
THE NEGATIVE IMPACT OF FAKE NEWS ON PUBLIC HEALTH SERVICES: REDUCING \\ VACCINATION AND ERADICATING DISEASES IN BRAZIL
}

\begin{abstract}
Flávia Piva Almeida Leite
Professora da Faculdade de Arquitetura, Artes e Comunicação - no Departamento de Ciências Humanas da FAAC/UNESP. Professora do Programa de Mestrado em Direito da UNESP/Franca. Tem experiência nos seguintes temas: relacionados à Administração Pública municipal e ao Direito Público, pessoa com deficiência, inclusão social, eliminação das barreiras arquitetônicas, desenho universal, acessibilidade, convenção dos direitos das pessoas com deficiência e direito urbanístico, sociedade da informação. Doutora em Direito do Estado pela PUC/SP na sub-área Direito Urbanístico , Mestrado pela Instituição Toledo de Ensino Bauru em Sistema Constitucional de Garantia de Direitos, pós graduada em Gerente de Cidades pela Fundação Armando Alvares Penteado - FAAP e Bacharel em Direito pela Instituição Toledo de Ensino de Bauru - ITE.

E-mail: flaviaaleite3@hotmail.com

Cintia Barudi Lopes

Doutora pela Pontifícia Universidade Católica de São Paulo (PUC/SP) em direito Administrativo. Professora da Universidade Presbiteriana Mackenzie e das Faculdades Metropolitanas Unidas. Advogada. Diretora da Comissão de Direito Administrativo da 116 Subseção da Saúde/Jabaquara.

E-mail: cbarudi@uol.com.br
\end{abstract}

\section{Fernanda Beatriz Monteiro Paes Gouvêa Barutti de Oliveira}

\begin{abstract}
Mestranda pela Pontifícia Universidade Católica de São Paulo (PUC/SP). Graduada em Fisioterapia, Centro Universitário São Camilo,2007. Graduada em Direito, Faculdades Metropolitanas Unidas, 2015.

E-mail: cbarudi@uol.com.br
\end{abstract}

Recebido em: 19/05/2019

Aprovado em: 22/05/2020

RESUMO: O presente estudo se destina a levantar a questão das Fake News e o seu papel prejudicial na diminuição dos índices de vacinação no Brasil com o reingresso de doenças até então consideradas erradicadas. Dedica-se, também, a abordar quais as medidas estatais que estão sendo tomadas para esclarecer as notícias falsas à população brasileira e incentivar os pais ou responsáveis a submeter seus filhos aos programas de imunização. A metodologia utilizada na elaboração do artigo considerou artigos científicos e doutrinas específicas sobre a matéria, permitindo entender que a informação somente pode ser considerada pressuposto da democracia quando encontra fundamento em bases verídicas de fatos e de ideais, de modo que o artigo nos faz refletir sobre o conflito existente nos tempos atuais entre a liberdade de informação e direito à saúde.

Palavras-chave: Fake News; Vacinação; Doenças; Erradicação. 
ABSTRACT: This study aims to raise the issue of Fake News and its harmful role in reducing vaccination rates in Brazil with the re-entry of diseases previously considered eradicated. It also focuses on what state measures are being taken to clarify the false news to the Brazilian population and encourage parents or guardians to submit their children to immunization programs. The methodology used in the elaboration of the article considered scientific articles and specific doctrines on the matter, allowing to understand that information can only be considered as a presupposition of democracy when it is based on a truthful basis of facts and ideals, so that the This article makes us reflect on the current conflict between freedom of information and the right to health.

Keywords: Fake New; Vaccinatio; Diseases; Eradication.

SUMÁRIO: Introdução; 1. As políticas públicas de melhoria da saúde no país; 2. Asnotícias falsas e seus impactos sociais; 3. As redes sociais e as fakenews; 4. Fakenews e a diminuição das campanhas de vacinação e reintrodução de doenças erradicadas; Considerações finais; Referências.

\section{INTRODUÇÃO}

O objetivo do presente artigo é analisar os efeitos maléficos que as Fake News vêm contribuindo para a diminuição dos índices de vacinação no país. Essas notícias falsas, divulgadas em especial ante a eventos específicos, como em épocas eleitorais, também são compartilhadas, sem nenhum critério de checagem, e estão influenciando negativamente as políticas públicas de vacinação, uma das maiores conquistas da população brasileira.

Inicia-se o artigo levantando a relação entre o direito à saúde, previsto constitucionalmente (art. 196 e 200 da Constituição Federal) e a obrigatoriedade de vacinação de crianças e adolescentes, como uma das principais políticas públicas de combate à mortalidade infantil, ainda com índices alarmantes no Brasil.

Em seguida, passa-se à análise da origem das Fake News e seus impactos sociais negativos. Segue-se a abordagem destacando, num terceiro ponto, como que as redes sociais e a sociedade da informação vêm contribuindo para o rápido trânsito dessas notícias, influenciando negativamente pais ou responsáveis a não vacinarem seus filhos e tutelados, colocando em risco a saúde coletiva de nossos habitantes e reintroduzindo doenças até então consideradas erradicadas.

Faz-se, por fim, uma abordagem sobre a diminuição dos índices de vacinação, seus riscos e ameaças ao direito constitucional de saúde e de saneamento básico, bem como se analisa quais as medidas que estão sendo tomadas pelos poderes públicos a fim de diminuir os impactos negativos dessas informações inverídicas.

A ausência de punição legal atribuída aos pais ou responsáveis também é um aspecto de preocupação levantada no artigo, uma vez que propicia a diminuição dos índices de vacinação cuja cobertura atualmente vem se apresentando aquém do desejado.

A metodologia utilizada na elaboração do artigo considerou artigos científicos, doutrinas específicas sobre a matéria, permitindo entender que a informação somente pode ser considerada pressuposto da democracia quando encontra fundamento em bases verídicas de fatos e de ideais, de modo que o artigo nos faz refletir sobre o conflito existente nos tempos atuais entre a liberdade de informação e direito à saúde.

\section{AS POLÍTICAS PÚBLICAS DE MELHORIA DA SAÚDE NO PAÍS}

O saneamento básico corresponde a uma série de políticas públicas voltadas à melhoria do meio físico onde a pessoa humana habita, visando criar melhores condições de salubridade a 
fim de assegurar a vida e a saúde dos habitantes de determinada localidade. Dessa forma, estabelece-se íntima relação entre o saneamento básico e a saúde da pessoa humana.

Modernamente, pode-se dizer que a saúde não é apenas a ausência de doença. Saúde é hoje tida como um conjunto de ações voltadas à melhoria da qualidade de vida da pessoa, como, por exemplo, o desenvolvimento de um ambiente saudável, pré-requisito indispensável para a saúde do homem, sendo certo que o saneamento básico, neste ponto, assume um papel imprescindível para que essas ações se aperfeiçoem.

De fato, a expressão "saneamento básico" aparece algumas vezes no texto da Constituição Federal de 1988. O primeiro dispositivo a se referir ao saneamento básico é o artigo 21, inciso XX, segundo o qual cabe à União, dentro de suas competências exclusivas, "instituir diretrizes para o desenvolvimento urbano, inclusive habilitação, saneamento básico e transportes urbanos".

A segunda passagem constitucional a respeito do saneamento básico está no artigo 200 da Constituição Federal, que define as competências do SUS - Sistema Único de Saúde, dentre as quais se encontram aquelas contidas no inciso IV de "participar da formulação da política e da execução das ações de saneamento básico" e no inciso VIII de "colaborar na proteção do meio ambiente, nele compreendido o do trabalho".

Nítida, portanto, até por disposição constitucional, é a relação entre o saneamento básico e a saúde, atribuindo-se ao SUS as competências de participar de políticas de saneamento básico e de proteção ao meio ambiente.

Assim, o constituinte colocou o saneamento básico como uma das políticas que a saúde deve buscar, além da proteção ao meio ambiente. Dessa forma, a saúde deve ser entendida como um estado de completo bem-estar físico, psíquico e principalmente social, não se resumindo à ausência de doenças.

Reportagem divulgada na revista Carta Capital $^{1}$, de 10 de setembro de 2008, demonstra que as crianças são as principais vítimas da falta de saneamento básico. Conforme divulgado nesta reportagem, "as principais vítimas da falta de saneamento são as crianças de 1 a 6 anos, que morrem mais nas vastas regiões onde há esgoto a céu aberto. De 1992 a2006, a média da população com acesso à coleta sanitária passou de $36 \%$ para $47 \%$."

Dados atuais, propriamente de 2018, demonstram que a situação ainda está preocupante. Conforme o Instituto Trata Brasil, em artigo sobre a situação do saneamento básico e a saúde da criança no Brasil, a exposição a ao esgoto ao céu aberto e a falta de água tratável são fatores que ainda afetam a saúde de crianças e jovens brasileiros.

No referido artigo $^{2}$ alerta-se que:

Os dados da Organização Mundial da Saúde (OMS) apontam que 10\% das doenças registradas ao redor do mundo poderiam ser evitadas se os países investissem mais em acesso à água, medidas de higiene e saneamento básico.Constatou-se que as crianças e jovens que moravam em áreas sem acesso aos serviços de coleta de esgoto tinham, em média, um atraso escolar 1,4\% superior ao daqueles que moravam em locais com coleta de esgoto.Os números são alarmantes, ainda mais quando falamos de mortalidade infantil. A taxa de mortalidade de crianças com até 5 anos de idade foi de 16,4 mortes por 1.000 nascidos vivos no Brasil em 2015. O reflexo desta realidade é que a diarréia mata 2.195 crianças por dia e faz mais vítimas do que a Aids, a malária e o sarampo juntos. É a segunda causa de morte entre meninos e meninas entre 1 mês e 5 anos no mundo.

\footnotetext{
${ }^{1}$ A mortalidade entre 1 e 6 anos é $24 \%$ maior onde há esgoto a céu aberto. Os investimentos chegarão a tempo para essas crianças? Revista Carta Capital, 10-9-2008.

2 Disponível em https://www.eosconsultores.com.br/saneamento-basico-para-saude-da-criancal. Acesso em 02/04/2019.
} 
Para que a mudança aconteça no Brasil, o país deve propor a solução definitiva nasáreas das políticas públicas, especialmente no campo da medicina preventiva e no setor de saneamento básico adequado. Sem essas medidas sociopreventivas é impossível modificar essa situação no país e assegurar um desenvolvimento sustentável das cidades e do meio ambiente nacional.

A baixa imunidade inerente às crianças, aliada ao fato de que elas estão expostas a doenças infecto contagiosas das mais variadas espécies, fazem com que o Estado forneça especial atenção a essa faixa etária, principalmente no que concerne à proteção contra doenças imunopreveníveis, como caxumba, sarampo, rubéola, difteria, poliomielite, entre outras.

A instituição de um Programa Nacional de Imunização, criado no Brasil em 1973 e concretizado pela Lei $\mathrm{n}^{\circ} 6.259 / 75$, aliado ao direito à saúde previsto na Constituição Federal de 1988, tem mitigado os riscos aos quais as crianças e adolescentes estão expostos.

O constituinte inseriu tanto a vacinação quanto o saneamento básico como políticas públicas que o direito à saúde deve concretizar, além da proteção ao meio ambiente, de forma a fazer com que esse direito seja entendido como um estado de completo bem-estar físico, psíquico e principalmente social.

No Brasil, nas últimas décadas, a preocupação com a redução da mortalidade infantil aumentou, razão porque houve um interesse maior da sociedade civil na contribuição de ações voltadas à solução e diminuição desses índices, notando-se uma maior atuação de organizações não-governamentais nesse sentido, além da implementação do SUS - Sistema Único de Saúde como um fator importante para a melhoria da questão em comento.

Vacinação em massa, programas de prevenção da saúde da gestante e da criança, eficiência nos tratamentos médicos, nutrição balanceada e adequada para a mãe e crianças são apenas algumas das medidas que poderão contribuir e que têm contribuído para a diminuição dos índices de mortalidade infantil.

No entanto, em detrimento de todo o esforço despendido e da evidente importância dos manejos sanitários e de saúde, nos últimos anos, temos presenciado o aumento de movimentos antivacinação.

Tal posicionamento aumenta na mesma proporção em que se consolida o acesso massivo à internet e se eleva a propagação de informações inverídicas, as chamadas fakenews no Brasil.

Passamos então a analisar como que essas falsas notícias têm contribuído negativamente para a diminuição da vacinação no país.

\section{ASNOTÍCIAS FALSAS E SEUS IMPACTOS SOCIAIS}

O Brasil é considerado, hoje, um dos países com maior número de produção, circulação e consumo de notícias falsas do mundo.

O Relatório da Segurança Digital no Brasil $(2018)^{3}$, demonstra que os índices de detecção de notícias falsas no Brasil, do primeiro para o segundo trimestre de 2018, aumentou de 50,6\% somando um total de 4,4 milhões de detecções - 1,5 milhão a mais que o observado no trimestre anterior.

De acordo com o relatório, a detecção tende a ser ainda maior em períodos que abarcam grandes eventos, como Copa do Mundo e eleições, adquirindo crescente atenção nos últimos anos.

Percebe-se verdadeira modificação na percepção e no comportamento das pessoas, caracterizando a perda da primazia da verdade como princípio estruturante da sociedade e das decisões de interesse público e privado. Assim, a indignação dá lugar à indiferença e, por fim, à conivência, o que permite o massivo alastramento das falsas informações.

Constata-se que as notícias falsas normalmente têm suas origens em situações que mexem com nossas convicções e ideologias. Alguns exemplos recentes indicam que tendemos a ser menos

${ }^{3}$ Disponível em https://www.psafe.com/dfndr-lab/pt-br/relatorio-da-seguranca-digital/. Acesso em 01/02/2019. Revista de Direito Brasileira | Florianólopis, SC | v. 25 | n. 10 | p. 142-161 | Jan./Abr. 2020 
céticos e cautelosos diante de "notícias" que vão ao encontro de nossos posicionamentos ideológicos ou que confirmem teses simpáticas à nossa forma de ver o mundo ${ }^{4}$.

Notícias falsas, na verdade, sempre existiram, mas hoje ganham proporções inimagináveis por conta da sociedade da informação em que vivemos.

Denise Paiero, professora de Jornalismo da Universidade Presbiteriana Mackenzie, Doutora e Mestre e Comunicação e Semiótica ${ }^{5}$, relembra um antigo fato de repercussão no país, e que não pode ser esquecido:

Imagine se, de uma hora para outra, sua vida fosse completamente destruída por um turbilhão de notícias sem fundamento. Foi exatamente o que aconteceu com seis pessoas em 1994, no que ficou conhecido como "caso Escola Base". O cenário era um colégio de classe média alta, localizado em bairro nobre da cidade de São Paulo. Naquele ano, os donos da escola, o responsável pelo transporte escolar e os pais de um dos alunos foram acusados de abusar sexualmente de crianças de 4 anos de idade, alunas da escola.A desconfiança partira de alguns pais e teria sido confirmada pelas próprias crianças. Outro fator importante: o delegado responsável pelo caso havia afirmado a jornalistas, antes da conclusão das investigações, que era grande a possibilidade de a história ser verdadeira.Munidos dessas informações, os principais veículos de comunicação do Brasil passaram a cobrir o assunto com destaque. A maioria já trazia uma espécie de condenação aos envolvidos, antes mesmo de a denúncia ser esclarecida pela polícia e sem que tivessem qualquer prova sobre o que afirmavam. $\mathrm{O}$ sensacionalismo na cobertura imperou. $\mathrm{O}$ caso se tornou um dos principais assuntos do país naquele momento. Como consequência, a escola foi fechada e depredada. Os denunciados chegaram a ser presos e passaram por um verdadeiro massacre: foram xingados, ameaçados de morte, agredidos. De uma hora para outra viram-se transformados nos grandes inimigos do país. Posteriormente, adoeceram, desenvolveram transtornos psiquiátricos, tiveram seus casamentos destruídos. Alguns ficaram meses se escondendo, com medo de sair de casa. Chegaram à falência financeira.Mas... com o andamento das investigações, todos os envolvidos foram inocentados. Nenhuma prova de que teriam cometido os abusos foi encontrada e o processo foi arquivado. Era tarde demais. As vidas dessas seis pessoas já estavam completamente destruídas, em grande parte por causa das notícias veiculadas pela mídia.O caso, em razão da sua gravidade, se tornou emblemático nas discussões sobre ética no jornalismo e um exemplo de como a propagação irresponsável de notícias pode ter consequências muito sérias.

A internet atualmente funciona como mecanismo de rápida propagação dessas notícias inverídicas, divulgando boatos que aparentemente são verdadeiros, mas cuja origem é de quase impossível identificação, muitas vezes com o intuito de prejudicar terceiros ou de produzir determinados resultados na órbita econômica, política ou social.

Nessa perspectiva, não deveríamos estar discutindo se uma notícia é falsa ou não; deveríamos, ao contrário, agravar a discussão mostrando que as notícias não são verdadeiras ou falsas, mas apenas uma versão da realidade; uma versão historicamente contextualizada, construída por alguém que possui interesses, identidades e subjetividade ${ }^{6}$.

Deparar-se com boatos e notícias falsas nas redes sociais e nos aplicativos de conversas, como Facebooke WhatsApp, virou uma prática constante, tendo em vista que as plataformas

\footnotetext{
${ }^{4}$ Disponível em https://www.mackenzie.br/fakenews/noticias/arquivo/n/a/i/fake-news-do-que-se-alimentam-comose-reproduzem/. Acesso em 26/04/2019.

${ }_{5}$ Disponível em https://www.mackenzie.br/fakenews/noticias/arquivo/n/a/i/escola-base-um-caso-que-nao-pode-seresquecido/. Acesso em 29/04/2019.

6 Disponível em https://www.revista-pub.org/blog/as-fake-news-e-os-conceitos-de-verdade-um-breve-panoramafilos\%C3\%B3fico. Acesso em 29/04/2019.
}

Revista de Direito Brasileira | Florianólopis, SC | v. 25 | n. 10 | p. 142-161 | Jan./Abr. 2020 
digitais servem como veículos instantâneos para canalizar o que há de mais instintivo em nós, incluindo nossos receios e preconceitos.

Tal fato, quando ausentes autoridades e empresas eficientes em oferecer ampla segurança, fica ainda mais evidente e preocupante. Basta citar, por exemplo, que as mensagens do WhatsAppsão criptografadas, tornando impossível o rastreamento da origem de qualquer conteúdo compartilhado no aplicativo.

Conclui-se, então, que esses são casos nos quais a privacidade e a liberdade de expressão têm um alto custo, com efeito negativos que vão além da esfera individual. Em que pese a dificuldade na valoração, deve-se dar prioridade à liberdade de expressão. Contudo, é necessária a reflexão sobre a existência ou não de limites para essa liberdade, que passa, por um lado, pela restrição e, por outro, pela desinformação ou mesmo manipulação de dados.

\section{AS REDES SOCIAIS E AS FAKENEWS}

Nos dias atuais, cada vez mais, as pessoas se organizam não em torno do que fazem, mas com base no que elas são ou acreditam quem são. Enquanto isso, as redes globais de intercâmbios instrumentais conectam e desconectam indivíduos, grupos, regiões e até países, de acordo com sua pertinência na realização dos objetivos processados na rede, em fluxo contínuo de decisões estratégicas. Segue-se uma divisão fundamental entre o instrumentalismo universal abstrato e as identidades particulares historicamente enraizadas. e o Ser. $^{7}$

Nossas sociedades estão cada vez mais estruturadas em uma oposição bipolar entre a Rede

Dentro desse contexto, a sociedade contemporânea vem adotando as Tecnologias de Informação e Comunicação (TCIs), em especial a internet, na vida social, econômica epública, como um local aberto e propício ao fomento de debates relativos a temas que em outros tempos eram discutidos apenas de forma presencial.

Todavia, o surgimento da era digital, tem suscitado a necessidade de repensar importantes aspectos relativos à organização social, à democracia, à tecnologia, à privacidade, à liberdade etc. Segundo Newton de Lucca “... assim como a Revolução Industrial modificou, no passado as feições do mundo moderno, a ainda incipiente Revolução Digital já está transformando as faces do mundo pós-moderno". 8

Dentre essas transformações podemos mencionar o conteúdo e limite que a liberdade de expressão e comunicação está sofrendo em um mundo cada vez mais interligado pela internet através das redes sociais.

A internet foi utilizada primeiramente pelos Estados Unidos, com finalidade bélica, passando, de mero meio de transmissão de informações a condição de local de encontro, debate e engajamento da defesa de movimentos sociais e políticos. Atualmente a internet é vista como um meio de comunicação que interliga dezenas de milhões de computadores no mundo inteiro e permite o acesso a uma quantidade de informações praticamente inesgotável, encurtando toda a distância de tempo e lugar.

Portanto, sob o aspecto técnico, a internet é uma imensa rede que liga elevado número de computadores em todo o planeta. E essas ligações surgem de inúmeras maneiras: redes telefônicas, cabos e satélites. Portanto, a rede telemática é uma oportunidade de encontros, de confronto, de

\footnotetext{
${ }^{7}$ Cf. CASTELLS, Manuel. A Sociedade em Rede(A era da informação: economia, sociedade e cultura; v.1. São Paulo: Paz e Terra, $9^{a}$ edição, Trad. RoneideVenancioMajer, 2006, p. 41.

${ }^{8}$ Cf. LUCCA, Newton de. Prefácio da $3^{a}$ edição da obra Direito digital de Patrícia Peck Pinheiro. $5^{\text {a }}$ edição. Editora Saraiva: São Paulo, 2014, p. 31.
}

Revista de Direito Brasileira | Florianólopis, SC | v. 25 | n. 10 | p. 142-161 | Jan./Abr. 2020 
troca de opiniões, de crescimento de relações interpessoais, com todas as vantagens e os riscos das relações sociais. ${ }^{9}$

Assim, com a internet surgem as redes sociais virtuais ou online quesão meios de comunicação em que não só brasileiros, mas outros cidadãos têm a possibilidade de ter contato com qualquer pessoa. Transmitem e recebem informações a todo tempo, de forma instantânea. Porém, nota-se que ocorre um desvio da finalidade das redes, porque os usuários passaram a escrever informações que entram na esfera privada e outras ainda, que ferem outros direitos fundamentais, provocando danos de diversas formas. ${ }^{10} \mathrm{E}$ assim, ultrapassando o direito à liberdade de expressão e pensamento.

Segundo aponta Martha Gabriel em sua obra Marketing na era digital, as redes sociais digitais são uma das formas de comunicação que mais crescem e difundem-se globalmente, alterando comportamentos e relacionamentos. E mais adiante, esclarece que a rede social é definida como uma estrutura social formada por indivíduos ou empresas, que são conectadas por um ou mais tipos específicos de interdependência, como amizade, parentesco, afinidade, trocas financeiras, relacionamento de crenças, relacionamento de conhecimento, relações sexuais etc. Portanto, é uma reunião da sociedade, cujo objetivo é buscar conectar pessoas e proporcionar a comunicação. Já as redes sociais na internet são páginas da web que criam mecanismos para facilitar a interação entre os seus membros, em diversos locais. ${ }^{11}$

As redes sociais no mundo virtual adquiriram grande importância e são muito utilizadas, uma vez que não existe concentração em uma única forma de relacionamento, mas um leque de espécies, além da horizontalidade das relações, não havendo hierarquia entre os participantes. Assim, essas redes sociais, tais como facebook ${ }^{12}$ são uma forma bastante utilizada pelas pessoas nos dias atuais onde interagem com as demais por diversos motivos, seja trabalho, relacionamento, estudo, diversão etc. ${ }^{13}$

Contudo, o que percebemos é que mesmo com todos os avanços nas áreas de segurança hoje disponíveis, a internet ainda tem se prestado a permitir que algumas pessoas abusem de todo o seu potencial para comunicação e interação: nunca testemunhamos tantos crimes e violações a direitos e garantias fundamentais dentro (e fora).

Assim, uma das grandes preocupações da sociedade digital hodiernamente é a propagação de notícias falsas. Segundo o Dicionário de Cambridge o conceito fakenews indica histórias falsas que, ao manterem a aparência de notícias jornalísticas, são disseminadas pela Internet (ou por outras mídias), sendo normalmente criadas para influenciar posições políticas, ou como piadas. ${ }^{14}$ Em geral, divulgar boatos não é um ato criminoso, desde que o boato não caracterize os delitos de calúnia, difamação e injúria, previstos no Código Penal. Há também a possibilidade de a notícia caracterizar crime de racismo, previsto no art. $20, \S 2^{\circ}$, da Lei 7718/89.

As fakenewscorrespondem a uma espécie de "imprensa marrom" (ou yellowjournalism), deliberadamente veiculando conteúdos falsos, sempre com a intenção de obter algum tipo de vantagem, seja financeira (mediante receitas oriundas de anúncios), política ou eleitoral.

\footnotetext{
${ }^{9}$ Cf. PAESANI, Lilliana Minardi. Direito e internet. Liberdade de informação, privacidade e responsabilidade civil. $6^{\text {a }}$ edição. Editora Atlas, São Paulo, 2013, p. 12.

${ }^{10}$ Cf. CARVALHO, Antonia Rafaela Fernandes. Twitter e facebook: liberdade de expressão e vida privada. Revista Direito e Liberdade. Natal, p. 41.

${ }^{11}$ Cf.GABRIEL, Martha. Marketing na era digital. São Paulo: Novatec, 2010, p. 193/194.

${ }^{12} \mathrm{O}$ Facebook foi criado pelo americano Mark Zuckerberg, quando este era aluno de Harvard, tendo inicialmente o nome Thefacebook. A rede funciona por meio de perfis e comunidades, podendo qualquer pessoa que deseje tornar-se membro criar uma conta. Ao realizar o cadastro e tornar-se membro, o primeiro passo é montar o perfil, em que são colocadas algumas informações pessoais. Feito o perfil, o indivíduo está pronto para formar a rede de amigos, bastando, para isso, ir ao perfil desejado, solicitar a amizade e aguardar a confirmação daquele membro. Essa rede social é uma forma bastante utilizada pelas pessoas atualmente para interagir com as demais por diversos motivos.

${ }^{13}$ Cf. CARVALHO, Antonia Rafaela Fernandes, p. 42.

${ }^{14} \mathrm{https} / / /$ dictionary.cambridge.org/us/dictionary/english/fake-news

Revista de Direito Brasileira | Florianólopis, SC | v. 25 | n. 10 | p. 142-161 | Jan./Abr. 2020
} 
Assim, a cada dia que a passa a internet tem se tornado o meio de comunicação mais usado intensamente no mundo inteiro, com este uso frequente por seus navegadores, surgem diversas redes sociais, onde cada um tem o livre aceso de publicação de sua vida, seus preceitos, seus gostos, suas políticas, bem como adicionar pessoas, postar fotos, jogos e uma infinidade de opções que proporciona na bendita e maldita rede social. Torna-se bendita porque é uma forma rápida e prática de contatar com o mundo afora, seja qual for o motivo; e maldita, porque muitos têm usado tais redes para denegrir a imagem humana, postando fotos íntimas nesses sites públicos, atacando com ofensas morais, o que tem ocasionado ofensa a direitos fundamentais, e gerado vários casos na justiça. ${ }^{15}$

Dentro desse contexto, pode-se verificar que os Estados têm se deparado, precipuamente, com alguns aspectos polêmicos do fakenews ocorridos nas redes sociais.

\section{FAKENEWS E A DIMINUIÇÃO DAS CAMPANHAS DE VACINAÇÃO E REINTRODUÇÃO DE DOENÇAS ERRADICADAS}

A vacinação é uma das medidas de política pública na área da saúde mais importantes e que está regida no Brasil pela Lei $n^{\circ}$ 6.259/75, regulamentada também pelo Decreto $n^{\circ} 78.231 / 76$ que criou o Programa Nacional de Imunizações (PNI), descrevendo a forma como a vacinação obrigatória deveria ser executada no Brasil: "serão obrigatórias, em todo o território nacional, as vacinações como tal definidas pelo Ministério da Saúde, contraas doenças controláveis por essa técnica de prevenção, consideradas relevantes no quadro nosológico nacional" (art. 27).

Além de criar e instalar a execução do PNI, referida norma regulou as ações de vigilância epidemiológica, vacinação e notificação compulsória de doenças no país e positivou o dever dos responsáveis por menores pela vacinação. A dispensa da imunização obrigatória somente é permitida a pessoa que apresentar Atestado Médico de contraindicação explícita da aplicação da vacina (Art. 29).

A Lei ${ }^{\circ}$ 8.069/90 - Estatuto da Criança e do Adolescente (ECA) - veio regulamentar o artigo 227 da Constituição Federal de 1988, estabelecendo direitos e proteção integral aos seus destinatários e, nesse contexto, reafirmou a obrigatoriedade de vacinação.

Tal obrigatoriedadeocorre porque a amamentação não deve ser considerada como único fator de proteção imunológica, tendo em vista a possibilidade de não produção ou produção insuficiente de leite pela lactante, a baixa cultura de amamentação com leite de terceiros, a maior inserção das mulheres no mercado de trabalho, abandonando a amamentação de maneira cada vez mais precoce, entre outros.

Ocorre que, mesmo as crianças consideradas saudáveis, submetidas à amamentação materna, quando não vacinadas, ao serem infectadas com patógenos causadores das doenças imunopreveníveis, correm riscos sérios de internação, desenvolvimento de sequelas e até mesmo de óbito.

No mais, acreditar que as doenças vacináveis estão erradicadas e controladas, confiar que as demais crianças foram vacinadas e que, por isso, todas estarão protegidas é um grave erro de interpretação. Somente atingindo e mantendo altas coberturas vacinais é que é possível proteger grandes parcelas da população, ano a ano.

Por isso, apesar da importância do aleitamento materno como fonte de células de defesa para a criança, ele, sozinho, não é capaz de imunizar as crianças contra todos os tipos de doenças passíveis de prevenção, mesmo nas crianças considerados saudáveis.

\footnotetext{
${ }^{15}$ Cf. TRENTIN, Taise Rabelo Dutra; TRENTIN, Sandro Seixas. Internet: publicações ofensivas em redes sociais e o direito à indenização por danos morais. Revista Direitos Emergentes na Sociedade Global. V.1, n.1, jan/jun/2012.ISSN 2316-3054, p. 81. Endereço de acesso: http://cascavel.cpd.ufsm.br/revistas/ojs2.2.2/index.php/REDESG/article/viewFile/6263/pdf. Revista de Direito Brasileira | Florianólopis, SC | v. 25 | n. 10 | p. 142-161 | Jan./Abr. 2020
} 
A compreensão e adesão dos pais e responsáveis é fundamental para a efetividade do sistema vacinal no país. Em geral, existe uma contribuição dos pais quanto à participação em campanhas de vacinação. A despeito disso, ainda há um percentual de pais resistentes à vacinação de seus filhos.

Com exceção de poucas mães, pode-se observar uma associação positiva entre o entendimento delas sobre a importância da imunização infantil e a atualização da caderneta de vacinação, notando-se que há participação, seja levando-as ao posto de saúde, seja fazendo abuscaativa das mesmas, seja por interesse em benefícios financeiros. ${ }^{16}$

Assim, em verdade, o que temos é que quanto mais ampla for a cobertura vacinal, mais reais os resultados observados na população. Quanto mais acurados esses resultados, melhores e mais significativas serão as pesquisas sobre possíveis melhorias e, quanto mais pesquisas forem realizadas, maiores as chances de desenvolvimento de novos produtos e meios de se combater as doenças significativas.

A despeito da importância da vacinação, crescem atualmente os boatos e as campanhas anti-vacinas, bem como as fakeNews acerca do tema, cujas notícias têm contribuído para o abandono crescente da vacinação.

"A vacina é mortal." "Essas doses já mataram milhares." "Não vacine seus filhos. É um risco." Frases como essas são amplamente compartilhadas nas redes sociais e aplicativos de mensagem como o WhatsApp. Ataques à vacina têm se tornado problema de saúde pública e preocupado especialistas. ${ }^{17}$

O peso dessas mensagens pode vir a ser grande o suficiente a ponto de toda uma geração ser diretamente afetada e, indiretamente, todas as próximas, causando novos surtos de doenças infecto contagiosas e grande dificuldade no manejo da situação.

Exemplos disso são as divulgações, já desmentidas, de que a vacinação pode causar autismo $^{18}$, que certos tipos de vacina causam câncer, entre outras, todas as notíciasinverídicasjá comprovadamente desmentidas.

\footnotetext{
${ }^{16}$ Bezerra Santos, Leiliane; Melquíades Barreto, Cristina Costa; Sepúlveda Sílva, Francisca Livia; de Oliveira Silva, Kamila Cristiane Percepção das mães quanto à importância da imunização infantil Revista da Rede de Enfermagem do Nordeste, vol. 12, núm. 3, julio-septiembre, 2011, pp. 621-626 Universidade Federal do Ceará Fortaleza, Brasil. Disponível em: http://www.redalyc.org/articulo.oa?id=324027976024

${ }^{17}$ Disponível em http://www2.senado.leg.br/bdsf/bitstream/handle/id/546210/noticia.html?sequence=1.
}

\footnotetext{
${ }^{18}$ Em décadas mais recentes, as controvérsias se focalizaram em eventos que envolveram as vacinas tríplice bacteriana e viral. No início dos anos 1970, um informe de um hospital pediátrico de Londres deu origem a uma polêmica internacional em torno da vacina DPT, ou tríplice bacteriana (contra a difteria, coqueluche e tétano). O relato informava que 36 crianças haviam desenvolvido problemas neurológicos após tomar a vacina e repercutiu amplamente nos jornais e redes de TV no Reino Unido. As taxas de vacinação caíram e ocorreram três grandes epidemias de coqueluche. Após esses eventos, autoridades de saúde britânicas conduziram um estudo nacional para investigar a associação entre a vacinação com a DPT e o surgimento de doenças neurológicas. Os resultados, publicados no Britsh Medical Journal em1978, mostraram que esse risco era muito baixo. No início dos anos 1980, a polêmica chegou aos Estados Unidos, com o lançamento do documentário DPT: VaccinationRoullete (DPT: A roleta da vacinação), que abordava os possíveis danos à saúde causados pela vacina e teve um grande impacto junto ao público americano. Mas o episódio que deu origem à maior polêmica mundial já criada em torno das vacinas, e que até hoje alimenta o debate antivacinação, se iniciou em 1998, quando o gastroenterologista britânico Andrew Wakefield publicou um estudo na prestigiada revista Lancet, que estabelecia uma relação entre a vacina MMR, ou tríplice viral (contra sarampo, caxumba e rubéola), e o desenvolvimento do autismo. De acordo com Wakefield, o preservantetimerosal, à base de mercúrio, que era usado nas vacinas, podia causar sérios danos neurológicos e intestinais nas crianças. $\mathrm{O}$ assunto teve grande repercussão na mídia. Seguiram-se uma crescente e sustentada redução nas taxas de vacinação no Reino Unido e o ressurgimento do sarampo no país. Em 2010, a revista Lancet publicou uma retratação formal sobre o estudo de Wakefield, afirmando que, além de problemas éticos e metodológicos - o trabalho se baseava na análise das amostras de um grupo de apenas 12 crianças, que haviam sido colhidas durante uma festa de aniversário do filho de Wakefield, mediante uma recompensa em dinheiro -, a pesquisa apresentava graves problemas de conflitos de interesse. Uma série de estudos investigativos sobre o tema foi realizada, mas não foi possível estabelecer uma conexão entre a vacina MMR, o timerosal e o autismo. O caso culminou com a cassação, em 2010, do direito de Wakefield exercer a medicina

Revista de Direito Brasileira | Florianólopis, SC | v. 25 | n. 10 | p. 142-161 | Jan./Abr. 2020
} 
Percebe-se que, com o aumento do acesso à informação, com a ampliação dos usuários da internet, que permitiria maior possibilidade de conferência daquilo que é real, o efeito foi inverso: ao invés de se utilizar do acesso à informação para dirimir dúvidas, grandeparcela da população se utiliza de tal meio apenas para dialogar entre seus pares, recebendo e enviando mensagens, as quais entendem como verdades inquestionáveis.

Otávio Augusto ${ }^{19}$, em manifestação sobre o assunto, alerta que:

Na última semana, as Sociedades Brasileiras de Pediatria (SBP), de Imunizações (SBIm) e Infectologia (SBI), em parceria com o Rotary Internacional sob o apoio do Programa Nacional de Imunizações (PNI), assinaram conjuntamente um manifesto que alerta para o risco de reintrodução da poliomielite e do sarampo no Brasil. "Diante do quadro atual, há necessidade da união de esforços de todos para a manutenção do país livre dessas doenças. As coberturas vacinais ainda são heterogêneas no Brasil, podendo levar à formação de bolsões de pessoas não vacinadas", destaca o documento.Atualmente, o Calendário Nacional de Vacinação do Ministério da Saúde contempla 19 vacinas, que são oferecidas pelo Sistema Único de Saúde (SUS) a toda a população. A Organização Mundial da Saúde (OMS) é categórica: a vacinação é a segunda maior conquista da saúde pública. Fica atrás somente do consumo de água potável. No entanto, o sucesso das ações de imunização - que teve como resultado a eliminação da poliomielite, do sarampo, da rubéola e da síndrome da rubéola congênita - têm causado em parte da população e — até mesmo em alguns profissionais de saúde — a falsa sensação de que não há mais necessidade de se vacinar. Um erro.O Ministério da Saúde garante que faz sua parte. O órgão estuda fortalecer a parceria com o Ministério da Educação para ampliar o Programa Saúde na Escola, que realiza o fortalecimento das ações de promoção, prevenção e atenção à saúde. A ideia é incrementar as ações de vacinação nas salas de aula. "Atuamos fortemente na disseminação de informações sobre vacinação em nossos meios de comunicação, seja por campanhas publicitárias, por meio de entrevistas de especialistas", adianta, em nota, sem revelar os detalhes.De nove vacinas prioritárias do calendário infantil, nenhuma atingiu a meta de $95 \%$ de imunização no ano passado. A maior parte delas ficou, em média, na casa dos $70 \%$. As vacinas que protegem contra o sarampo tiveram queda. A tríplice viral passou de $96 \%$ de cobertura da população em 2015 , para $83,87 \%$ no ano passado. A tetra viral saiu de 77,37\% para 70,6\% no mesmo período. O mesmo aconteceu com a tetra viral, poliomielite, BCG, Rotavírus humano, Meningocócica C, Pentavalente e Pneumocócica.Para melhorar os índices, uma campanha nacional de vacinação será realizada entre 6 e 31 de agosto. Em 18 de agosto, um sábado, postos de saúde em todo o Brasil estarão abertos para imunizar quem não recebeu doses da vacina. A apresentadora Xuxa Meneghel será madrinha da campanha. "Esse papo de 'não precisa vacinar' não' é mentira. Quem está falando isso é mentiroso. Tem que vacinar, sim. Se você ama o seu baixinho, se você ama a sua baixinha, vamos vacinar", reforça a apresentadora no vídeo institucional que ainda será lançado.

no Reino Unido e, em 2011, com a classificação de seu artigo pelo British Medical Journal como uma "falsificação elaborada". O médico britânico é considerado hoje um mártir por segmentos antivacinistas. Mudou-se para o Canadá, fundou o site Age ofAuthism (Era do Autismo) e segue militando contra a vacinação. Disponível em http://comciencia.scielo.br/scielo.php?script=sci_arttext\&pid=S1519-76542014000800006\&lng=es\&nrm=iso.

Acesso em 05/05/2019.

19 Augusto, Otávio. Fake News ameaçam vacinação. Correio braziliense, n. 20157, 30/06/2018. Política, p. 4.Disponívelem http://www2.senado.leg.br/bdsf/bitstream/handle/id/546210/noticia.html?sequence=1. Acesso em 05/05/2019.

Revista de Direito Brasileira | Florianólopis, SC | v. 25 | n. 10 | p. 142-161 | Jan./Abr. 2020 
Diante desse quadro preocupante, em que pese a obrigatoriedade da vacinação infantil, inexiste lei que estipule punição para seu descumprimento. Sempre que a lei estabelece um dever, para que esse dever seja de fato cumprido pelos cidadãos, a legislação prevê um conjunto de possíveis sanções a serem aplicadas contra aqueles que não cumprirem o dever legal.

Ocorre que, no caso da vacinação, o único controle estatal ao cumprimento da lei é realizado por meio da exigência da cópia da carteira de vacinação dos filhos na ocasião de matrícula em creche pública ou pelo pedido da comprovação de vacinação para obtenção do benefício da bolsa família, ou para prestar concursos públicos ou, ainda, para o ingresso em um cargo público.

Não há sanção propriamente dita ou, ainda, pode-se inferir que a penalidade existente somente atinge a própria criança/pessoa não vacinada. Os responsáveis, os quais deveriam ter seguido as orientações de saúde pública, saem ilesos, exceto, é claro, quando punidos pelo adoecimento de seus filhos ou mesmo pela sua perda em decorrência da doença.

Analisando ascircunstâncias da realidade brasileira, considerandoas incipientes campanhas antivacina e a crise migratória venezuelana, que traz consigo novamente diversas doenças já erradicadas em terras tupiniquins, há de se considerar que algo deve ser feito para cessar ou, ao menos, fazer com que tal quadro seja atenuado ${ }^{20}$.

Nesse sentido, Ramon Armani Pontini e Daury César Fabriz ${ }^{21}$, esclarecem:

Nesta classificação trazida pelo autor José Nabais, há de se considerar que quando um indivíduo se nega a vacinar sua prole ou tutelado, ele estará a violar 3 (três) dos 4 (quatro) deveres dos quais a ele são destinados e, consequentemente, lesando os titulares destes.Quando não vacina aquele por quem é responsável, o cidadão estará a desvincular-se da coletividade, pois, levando à cabo teorias já desmentidas cientificamente, prejudicará o todo social que está ao seu redor, das pessoas que, não tendo condição estrutural ou física para vacinar-se, possam vir a contrair o vírus da doença, trazido de outraspartes do mundo ou até mesmo no contato com animais.Também estará se desvinculando de seu dever em relação aoutros indivíduos, diretamente, podendo acarretar possíveis consequências, seja em um futuro próximo ou distante, a seus protegidos e, no caso destes ainda estarem em sua tutela quando vierem a serem infectados por determinada doença, a si mesmos.Portanto, na maioria dos casos, ao lesar aquele que seria o titular do dever fundamental, portanto, quem deveria se beneficiar dele, por intermédio do pleno gozo do direito à saúde, estará não lesando um ente meramente abstrato -a coletividade -, mas àquele por quem conserva um dever de cuidado, e, em alguns casos, a si mesmo.

Deve-se sempre ter em mente que o ganho com a imunização vai além da esfera individual, pois a redução da circulação desses agentes e doenças na população também leva a um grande benefício coletivo, que inclui menores taxas de hospitalização e de sequelas (osarampo, por exemplo, pode provocar surdez e problemas neurológicos).

Além disso, sabe-se que muitas dessas doenças, quando adquiridas na idade adulta, podem gerar sequelas e acometimentos muito mais graves do que na infância. Não obstante, não se sabe como a doença se manifestará em cada organismo. Nem se fale no risco de contaminação em países estrangeiros, trazendo de volta ao Brasil doenças já erradicadas, como temos visto recentemente.

Deve-se ter consciência de que a vacinação é para a vida. Infelizmente, percebe-se que o aumento do acesso à informação, não necessariamente simboliza a libertação das massas em relação ao controle efetuado por minorias.

\footnotetext{
${ }^{20} \mathrm{O}$ dever fundamental dos Pais e Tutores de colaborarem para com o sistema de saúde público por meio da vacinação de seus filhos e tutelados. Disponível em https://nx.derechoycambiosocial.com/ojs-3.1.14/index.php/derechoycambiosocial/article/view/21/38. Acesso em 05/05/2019.

${ }^{21}$ Ibidem, mesma data.
} 
Nessa toada, inafastável a reflexão sobre a necessidade de organização e de reorganização das dinâmicas e das medidas a serem tomadas acerca do saneamento básico, momento a momento, e que considere a inserção das informações formais coletadas, bem como a existência de informações amplamente distribuídas pela própria população, sejam elas verdadeiras ou não.

Isso porque, tanto as informações oficiais quanto as inverídicas causarão impactos diretos e profundos na população em questão, requerendo o confronto da realidade e a adequação das medidas estatais frente ao quadro observado.

Ou seja, não basta a simples programação de políticas públicas com base nos registros estatais de informações acerca das peculiaridades daquela comunidade. Há que se pensar, também, nos efeitos - positivos e deletérios - das distorções da informação que chegam aos seus receptores, prevendo-se, inclusive, possíveis resistências às medidas propostas, bem como alterações fáticas no momento da implantação de tais políticas, causadas pela organização da própria população, com lastro nas informações obtidas, sejam elas fidedignas ou não.

Importante, então, cuidar para que não haja descompasso entre a produção e a disseminação dos dados oficiais. Sem essa cautela, naturalmente facilita-se a dispersão de dados e de informações falsas, especialmente pela inexistência de um sistema de informações que articule e integre, com eficiência, os dados de saneamento básico no país, comprometendo a eficaz participação e o controle social, ambos previstos na Lei ${ }^{\circ} 11.445 / 2007$.

Mais uma vez a conscientização da sociedade é a melhor medida a ser tomada. Conscientizar as pessoas a checar as notícias antes de repassá-las pode contribuir para a diminuição do trânsito dessas informações inverídicas. Entender que a democracia somente pode ser alcançada quando a discussão de ideias se baseia em fatos reais é um bom começo para que a transmissão de notícias falsas não seja um fator determinante para a falência de uma sociedade democrática de direito.

Façamos, então, a nossa parte.

\section{CONSIDERAÇÕES FINAIS}

As políticas públicas na área da saúde visam amelhoria dos serviços públicos de saneamento, tais como, esgotamento sanitário, distribuição de água potável, e em especial aquelas voltadas à prevenção da mortalidade infantil cujos índices no país ainda são bastante alarmantes.

A Política Nacional de Imunizações (PNI) e o Estatuto da Criança e do Adolescente são normas que impõem a obrigatoriedade de vacinação conforme estabelecido pelo Ministério da Saúde.

Ocorre, porém, que a despeito dessa obrigatoriedade, notícias falsas veiculadas pelas mídias sociais vêm contribuindo para a diminuição dos índices dos programas de vacinação no Brasil, bem como para o retorno de doenças até então consideradas erradicadas.

Com a necessidade de adequação ao momento em que vivemos, na sociedade da informação, e com o fim de combater as sobre saúde, em especial no que tange ao programa de vacinação, o Ministério da Saúde disponibiliza um número de WhatsApp para envio de mensagens pela população. fakenews

Adverte que não se trata de um SAC ou canal para esclarecimento de dúvidas dos usuários, mas um espaço exclusivo para receber informações virais. O intuito é de que tais mensagens sejamapuradas pelas áreas técnicas e respondidas, oficialmente, se são verdadeiras ou não.

Ao mesmo tempo, com o intuito de diminuir os índices negativos da vacinação, o Estado vem estabelecendo algumas medidas estimuladoras aos pais ou responsáveis, visandoincentivar cada vez mais a manutenção atualizada da carteira de vacinação de seus filhos. 
Atualmente, há um movimento no país no sentido de exigir, por orientação dos órgãos públicos competentes, a cópia da carteira de vacinação dos filhos na ocasião de matrícula em creche pública e a necessidade de comprovação de vacinação para obtenção do benefício da bolsa família.

Tais medidas podem até ser eficazes quando se tratarem de pessoas dependentes desses benefícios. No entanto, grande parcela da população que não vacina suas crianças não faz parte do estrato socioeconômico que utiliza os referidos serviços e programas.

Portanto, ainda temos, no Brasil, dois pesos e duas medidas, sendo que a população mais carente de cuidados de saúde acaba sendo também a mais prejudicada, em outras áreas, pelas consequências da não vacinação de suas crianças. Para as famílias com maior poder econômico, como há menor dependência dos serviços que requerem a vacinação como condição, nos parece que não há qualquer tipo de sanção ou restrição.

Dessa maneira, verificasse que estamos apenas engatinhando em termos de medidas sancionatórias adotadas para coibir a não vacinação de nossas crianças. Também fica evidente que ainda estamos nos primórdios das táticas de eliminação de divulgação das fakeNews, que hoje representam uma realidade incontestável.

Infelizmente, o que se percebe é o lado negativo da dita sociedade da informação. Informação é um direito fundamental garantido constitucionalmente. Mas, não basta o acesso à informação. É preciso, antes de qualquer outra medida, educar a população para que ela, por si só, possa discernir a boa e a má informação. A educação e conscientização social é um passo primordial nessa luta, além de um pressuposto daprópria democracia.

\section{REFERÊNCIAS}

BARBIERI, CLA; COUTO, MT; AITH, FMA. A (não) vacinação infantil entre a cultura e a lei: os significados atribuídos por casais de camadas médias de São Paulo, Brasil. Cad. Saúde Pública 2017; 33(2): e00173315. Disponível em: http://www.scielo.br/pdf/csp/v33n2/1678-4464csp-33-02-e00173315.pdf. Acesso em 23 de janeiro de 2019.

BAXTER, R; TRAN, TN; RAY, P; LEWIS, E; FIREMAN, B; BLACK, S; et al. Impactofvaccinationontheepidemiologyofvaricella: 1995- 2009. Pediatrics. 2014;134:24-30. Apud HIROSE, M; GILIO, AE; FERRONATO, AE. et al. Impacto da vacina varicela nas taxas de internações relacionadas à varicela: revisão de dados mundiais. Rev Paul Pediatr. 2016;34(3):359---366. Disponível em: http://www.scielo.br/pdf/rpp/v34n3/pt_0103-0582-rpp-3403-0359.pdf. Acesso em 23 de janeiro de 2019.

BRASIL. Constituição da República Federativa do Brasil. Brasília, DF: Senado Federal: Centro Gráfico, 1988. Disponível em: http://www.planalto.gov.br/ccivil_03/constituicao/constituicao compilado.htm. Acesso em 23 de janeiro de 2019.

BRASIL. Decreto $n^{\circ} 78.231$, de 12 de agosto de 1976. Regulamenta a Lei $n^{\circ} 6.259$, de 30 de outubro de 1975, que dispõe sobre a organização das ações de Vigilância Epidemiológica, sobre o Programa Nacional de Imunizações, estabelece normas relativas à notificação compulsória de doenças, e dá outras providências. DOU de 13.8.1976. Disponível em:

http://www.planalto.gov.br/ccivil_03/decreto/1970-1979/D78231.htm. Acesso em 23 de janeiro de 2019.

BRASIL. Lei $n^{\circ}$ 6.259, de 30 de outubro de 1975. Dispõe sobre a organização das ações de vigilância epidemiológica, sobre o programa nacional de imunizações, estabelece normas 
relativas à notificação compulsória de doenças, e dá outras providências. Diário Oficial da União 1975; 31 out. Disponível em: http://www.planalto.gov.br/ccivil_03/LEIS/L6259.htm. Acesso em 23 de janeiro de 2019.

BRASIL. Lei $n^{o} 8.069$, de 13 de julho de 1990. Dispõe sobre o Estatuto da Criança e do Adolescente e dá outras providências. DOU 16.7.1990. Disponível em:

http://www.planalto.gov.br/ccivil_03/LEIS/L8069.htm. Acesso em 23 de janeiro de 2019.

BRASIL. Lei $n^{\circ}$ 8.142, de 28 de dezembro de 1990. Dispõe sobre a participação da comunidade na gestão do Sistema Único de Saúde (SUS) e sobre as transferências intergovernamentais de recursos financeiros na área da saúde e dá outras providências. DOU de 31.12.1990. Disponível em: http://www.planalto.gov.br/ccivil_03/leis/L8142.htm. Acesso em 23 de janeiro de 2019.

BRASIL. Ministério da Saúde (MS). Secretaria de Políticas de Saúde. Projeto Promoção da Saúde. As Cartas da Promoção da Saúde. Brasília: MS; 2002. Apud SOUSA, IV; BRASIL, CCP; SILVA, RM; et al. Diagnóstico participativo para identificação de problemas de saúde em comunidade em situação de vulnerabilidade social. Ciência \& Saúde Coletiva, 22(12):3945-3954, 2017. Disponível em: http://www.scielo.br/pdf/csc/v22n12/1413-8123-csc-22-12-3945.pdf. Acesso em 23 de janeiro de 2019.

BRASIL. Ministério da Saúde. Blog da Saúde [homepage onthe Internet]. Vacina contra varicela passa a ser ofertada pelo SUS. Publicado em 02 de setembro 2013. Disponível em: http://www.blog.saude.gov.br/index.php?id=32893:vacina-contra-catapora-e-oferecida-pelo-sus. Apud HIROSE, M; GILIO, AE; FERRONATO, AE. et al. Impacto da vacina varicela nas taxas de internações relacionadas à varicela: revisão de dados mundiais. Rev Paul Pediatr. 2016;34(3):359---366. Disponível em: http://www.scielo.br/pdf/rpp/v34n3/pt_0103-0582-rpp-3403-0359.pdf. Acesso em 23 de janeiro de 2019.

BRASIL. Ministério da Saúde. Guia de vigilância em saúde. Brasília: Ministério da Saúde; 2014. Apud MEDEIROS, ATN; CAVALCANTE, CAA; SOUZA, NL; FERREIRA, MAF. Perfil da reemergência da coqueluche. Cad. Saúde Colet., 2017, Rio de Janeiro, 25 (4): 453-459.

Disponível em: http://www.scielo.br/pdf/cadsc/v25n4/1414-462X-cadsc-25-4-453.pdf. Acesso em 23 de janeiro de 2019.

BRASIL. Ministério da Saúde. Saúde sem Fake News. Disponível em: http://portalms.saude.gov.br/fakenews?limitstart=0. Sem data. Acesso em 24 de janeiro de 2019.

BRASIL. Ministério da Saúde. Saúde sem Fake News. VACINAS CAUSAM AUTISMO - FAKE NEWS. Publicado em 24 de Setembro de 2018. Disponível em:

http://portalms.saude.gov.br/fakenews/44429-vacinas-causam-autismo-fake-news. Acesso em 24 de janeiro de 2019.

BRASIL. Ministério da Saúde. Secretaria de Vigilância em Saúde. Departamento de Vigilância das Doenças Transmissíveis. Manual de vigilância de eventos adversos pós-vacinação. 3 ed. Brasília; 2014. Apud LINHEIRA-BISETTO LH, CIOSAK SI. Analysisof adverse eventsfollowingimmunizationcausedbyimmunizationerrors. RevBrasEnferm [Internet]. 2017;70(1):81-9. Disponível em: http://dx.doi.org/ 10.1590/0034-7167-2016-0034. Acesso em 23 de janeiro de 2019 . 
BRICKS LF. Pertussis: novas estratégias de vacinação para prevenção de uma antiga doença. $J$ Health BiolSci. 2013;1(2):73-83. http://dx.doi. org/10.12662/2317-3076jhbs.v1i2.19.p73.2013. Apud MEDEIROS, ATN; CAVALCANTE, CAA; SOUZA, NL; FERREIRA, MAF. Perfil da reemergência da coqueluche. Cad. Saúde Colet., 2017, Rio de Janeiro, 25 (4): 453-459, p.454. Disponível em: http://www.scielo.br/pdf/cadsc/v25n4/1414-462X-cadsc-25-4-453.pdf. Acesso em 23 de janeiro de 2019.

BRICKS, LF; SATO, HK; OSELKA, GW.Vacina contra varicela e vacina quádrupla viral. $J$ Pediatr (Rio J). 2006;82 Suppl 3:S101-8. Apud HIROSE, M; GILIO, AE; FERRONATO, AE. et al. Impacto da vacina varicela nas taxas de internações relacionadas à varicela: revisão de dados mundiais. Rev Paul Pediatr. 2016;34(3):359---366. Disponível em: http://www.scielo.br/pdf/rpp/v34n3/pt_0103-0582-rpp-34-03-0359.pdf. Acesso em 23 de janeiro de 2019.

CENTRO de Vigilância Epidemiológica "Prof. Alexandre Vranjac". Alerta sarampo 2015. http:// www.cve.saude.sp.gov.br/htm/resp/pdf/Aler ta_Sarampo_2015_jan_rev.pdf (acessado em 03/ Mar/2015). Apud BARBIERI; CLA; COUTO, MT; AITH, FMA. A (não) vacinação infantil entre a cultura e a lei: os significados atribuídos por casais de camadas médias de São Paulo, Brasil. Cad. Saúde Pública 2017; 33(2): e00173315. Disponível em: http://www.scielo.br/pdf/csp/v33n2/1678-4464-csp-33-02-e00173315.pdf. Acesso em 23 de janeiro de 2019.

CONDURÚ, M.T. e PEREIRA, J.A.R. Gestão da informação em saneamento básico no Estado do Pará sob o enfoque do ciclo informacional. EngSanitAmbient | v.22 n.6 | nov/dez 2017 | 12251232. Disponível em: http://www.scielo.br/pdf/esa/v22n6/1809-4457-esa-22-06-1225.pdf. Acesso em 23 de janeiro de 2019.

COSTA, NMN; LEÃO, AMM. Casos notificados de eventos adversos pós-vacinação: contribuição para o cuidar em enfermagem. RevEnferm UERJ [Internet]. 2015;23(3):297-303. Disponível em: http://www.facenf.uerj.br/v23n3/v23n3a02.pdf. Apud LINHEIRA-BISETTO LH, CIOSAK SI. Analysisof adverse eventsfollowingimmunizationcausedbyimmunizationerrors. RevBrasEnferm [Internet]. 2017;70(1):81-9. Disponívelem: http://dx.doi.org/ 10.1590/00347167-2016-0034. Acesso em 23 de janeiro de 2019.

COTTA, RMM; MARTINS, PC; BATISTA, RS; FRANCESCHINNI, SCC; PRIORE, SE; MENDES, FF. O controle social em cena: refletindo sobre a participação popular no contexto dos Conselhos de Saúde. Physis2011; 21(3):1121- 1138. Apud SOUSA, IV; BRASIL, CCP; SILVA, RM; et al. Diagnóstico participativo para identificação de problemas de saúde em comunidade em situação de vulnerabilidade social. Ciência \& Saúde Coletiva, 22(12):3945-3954, 2017. Disponível em: http://www.scielo.br/pdf/csc/v22n12/1413-8123-csc-22-12-3945.pdf. Acesso em 23 de janeiro de 2019.

CRUZ JUNIOR, Gilson. Resenha crítica. D'ANCONA, Matthew. Pós-verdade: a nova guerra contra os fatos em tempos de fakenews. Barueri: Faro Editorial, 2018. ETD- Educação Temática Digital Campinas, SP v.21 n.1 p.278-284 jan./mar. 2019. Disponível em: https://periodicos.sbu.unicamp.br/ojs/index.php/etd/article/view/8652833.Acesso em 23 de janeiro de 2019. 
CRUZ JUNIOR, Gilson. Resenha crítica. D'ANCONA, Matthew. Pós-verdade: a nova guerra contra os fatos em tempos de fakenews. Barueri: Faro Editorial, 2018. ETD- Educação Temática Digital Campinas, SP v.21 n.1 p.278-284 jan./mar. 2019. Disponível em: https://periodicos.sbu.unicamp.br/ojs/index.php/etd/article/view/8652833.Acesso em 23 de janeiro de 2019.

D’ANCONA, Matthew. Post Truth. Vídeo. Publicado em 24 jul 2017 Disponível em https://archive.org/details/POST_TRUTH_with_Matthew_d_Ancona. Acesso em 23 de janeiro de 2019.

DIZIKES, Peter. ARAL, Sinan; ROY, Deb; VOZOUGHI, Soroush. Study: OnTwitter, false newstravelsfasterthantruestories: Researchprojectfindshumans, notbots, are primarilyresponsible for spread ofmisleadinginformation. MIT News Office. March 8, 2018.Disponívelem: http://news.mit.edu/2018/study-twitter-false-news-travels-faster-true-stories-0308. Acesso em 23 de janeiro de 2019. Apud

DOCTOR, A; HARPER, MB; FLEISHER, GR. Group A beta-hemolyticstreptococcalbacteremia: historical overview, changingincidence, andrecentassociationwithvaricella. Pediatrics. 1995;96:428-33. Apud HIROSE, M; GILIO, AE; FERRONATO, AE. et al. Impacto da vacina varicela nas taxas de internações relacionadas à varicela: revisão de dados mundiais. Rev Paul Pediatr. 2016;34(3):359---366. Disponível em: http://www.scielo.br/pdf/rpp/v34n3/pt_01030582-rpp-34-03-0359.pdf. Acesso em 23 de janeiro de 2019.

ENGLEITNER, F; MOREIRA, AC; Incidência de rubéola, caxumba e sarampo no município de Ijuí/RS entre os anos de 1995 e 2007. Rev Contexto Saúde. 2008 jan-jun;7(14):37-44. Apud MOURA, ADA; CARNEIRO, AKB; BRAGA, AVL; et al. Estratégias e resultados da vacinação no enfrentamento da epidemia de sarampo no estado do Ceará, 2013-2015 Epidemiol. Serv. Saúde, Brasília, 27(1):e201634310, 2018. Disponível em: https://scielosp.org/pdf/ress/2018.v27n1/e201634310. Acesso em 23 de janeiro de 2019.

FERNANDES, EG; OLIVEIRA, MEB; FRED, J; et al. Surto de sarampo na região metropolitana de Campinas, SP. Rev Saúde Pública. 2013 ago;47(6):1213-7. Apud MOURA, ADA; CARNEIRO, AKB; BRAGA, AVL; et al. Estratégias e resultados da vacinação no enfrentamento da epidemia de sarampo no estado do Ceará, 2013-2015 Epidemiol. Serv. Saúde, Brasília, 27(1):e201634310, 2018. Disponível em: https://scielosp.org/pdf/ress/2018.v27n1/e201634310. Acesso em 23 de janeiro de 2019.

GALIL, K; BROWN, C; LIN, F; SEWARD, J. Hospitalizations for varicella in the United States, 1988 to 1999.PediatrInfectDis J. 2002;21:931-4. Apud HIROSE, M; GILIO, AE; FERRONATO, AE. et al. Impacto da vacina varicela nas taxas de internações relacionadas à varicela: revisão de dados mundiais. Rev Paul Pediatr. 2016;34(3):359---366. Disponível em: http://www.scielo.br/pdf/rpp/v34n3/pt_0103-0582-rpp-34-03-0359.pdf. Acesso em 23 de janeiro de 2019.

GARVEY, W.D. Communication: theessenceofscience. Oxford: Pergamon, 1979. Apud CONDURÚ, M.T. e PEREIRA, J.A.R. Gestão da informação em saneamento básico no Estado do Pará sob o enfoque do ciclo informacional. EngSanitAmbient | v.22 n.6 | nov/dez 2017 | 1225- 
1232. Disponível em: http://www.scielo.br/pdf/esa/v22n6/1809-4457-esa-22-06-1225.pdf. Acesso em 23 de janeiro de 2019.

GRAGNANI, Juliana. Para mandar no grupo da família: um guia de como checar se uma notícia é falsa. BBC News Brasil em Londres. 14 setembro 2018. Disponível em: https://www.bbc.com/portuguese/brasil-45043716. Acesso em 23 de janeiro de 2019.

HARTMANN, M. Vacinar ou não vacinar: eis a questão. O Estado de S. Paulo, São Paulo, Publicado em 06/09/2016. Disponível em: https://emais.estadao.com.br/noticias/bemestar,vacinar-ou-nao-vacinar-eis-a-questao,10000074325. Acesso em 23 de janeiro de 2019.

HARTMANN, Marcel. Conheça a origem do movimento antivacina. O Estado de S. Paulo, São Paulo, 06/09/2016. Disponível em: https://emais.estadao.com.br/noticias/bem-estar,conheca-aorigem-do-movimento-antivacina,10000074329. Acesso em 23 de janeiro de 2019.

HEIDMANN, ITSB; ALMEIDA, MCP; BOEHS, AE; WOSNY, AM; MONTICELLI M. Promoção à saúde: trajetória histórica de suas concepções. Texto contexto - enferm; 15(2):352358. 2006. Apud SOUSA, IV; BRASIL, CCP; SILVA, RM; et al. Diagnóstico participativo para identificação de problemas de saúde em comunidade em situação de vulnerabilidade social. Ciência \& Saúde Coletiva, 22(12):3945-3954, 2017. Disponível em: http://www.scielo.br/pdf/csc/v22n12/1413-8123-csc-22-12-3945.pdf. Acesso em 23 de janeiro de 2019.

HENRIQUES, MSH; MAFRA, RLM. Mobilização social em saúde: o papel da comunicação estratégica. In: SANTOS A (organizador). Caderno mídia e saúde pública. Belo Horizonte: Escola de Saúde Pública, FUNED; 2006. p. 101-111. Apud SOUSA, IV; BRASIL, CCP; SILVA, RM; et al. Diagnóstico participativo para identificação de problemas de saúde em comunidade em situação de vulnerabilidade social. Ciência \& Saúde Coletiva, 22(12):3945-3954, 2017. Disponível em: http://www.scielo.br/pdf/csc/v22n12/1413-8123-csc-22-12-3945.pdf. Acesso em 23 de janeiro de 2019.

LANCASTER, F.W. Pautas para laevaluación de sistemas y servicios de información. Paris: UNESCO, 1980. Apud CONDURÚ, M.T. e PEREIRA, J.A.R. Gestão da informação em saneamento básico no Estado do Pará sob o enfoque do ciclo informacional. EngSanitAmbient | v.22 n.6 | nov/dez 2017 | 1225-1232. Disponível em: http://www.scielo.br/pdf/esa/v22n6/18094457-esa-22-06-1225.pdf. Acesso em 23 de janeiro de 2019.

LINHEIRA-BISETTO LH, CIOSAK SI. Analysisof adverse eventsfollowingimmunizationcausedbyimmunizationerrors. RevBrasEnferm [Internet]. 2017;70(1):81-9. Disponível em: http://dx.doi.org/ 10.1590/0034-7167-2016-0034. Acesso em 23 de janeiro de 2019.

MARTÍNEZ, Marcos. Como as 'fakenews' no WhatsApp levaram um povoado a linchar e queimar dois homens inocentes.BBC News Brasil 14 novembro 2018. Disponível em: https://www.bbc.com/portuguese/salasocial-46206104. Acesso em 23 de janeiro de 2019. 
MCINTYRE, Lee. Post-truth. Cambridge: The MIT Press, 2018. Apud CRUZ JUNIOR, Gilson. Resenha crítica. D'ANCONA, Matthew. Pós-verdade: a nova guerra contra os fatos em tempos de fakenews. Barueri: Faro Editorial, 2018. ETD- Educação Temática Digital Campinas, SP v.21 n.1 p.278-284 jan./mar. 2019. Disponível em:

https://periodicos.sbu.unicamp.br/ojs/index.php/etd/article/view/8652833. Acesso em 23 de janeiro de 2019.

MONTEIRO, SAMG; TAKANO, AO; WALDMAN EA. Avaliação do sistema brasileiro de vigilância de eventos adversos pós-vacinação. RevBrasEpidemiol [Internet]. 2011;14(3):361-71. Disponível em: http://dx.doi. org/10.1590/S1415-790X2011000300002. Apud LINHEIRABISETTO LH, CIOSAK SI. Analysisof adverse eventsfollowingimmunizationcausedbyimmunizationerrors. RevBrasEnferm [Internet]. 2017;70(1):81-9. Disponível em: http://dx.doi.org/ 10.1590/0034-7167-2016-0034. Acesso em 23 de janeiro de 2019.

MORAES, JC; RIBEIRO, MCSA; SIMÕES, O; CASTRO, PC; BARATA, RB. Qual a cobertura vacinal real? EpidemiolServ Saúde 2003; 12:147-53. Apud BARBIERI; CLA; COUTO, MT; AITH, FMA. A (não) vacinação infantil entre a cultura e a lei: os significados atribuídos por casais de camadas médias de São Paulo, Brasil. Cad. Saúde Pública 2017; 33(2): e00173315. Disponível em: http://www.scielo.br/pdf/csp/v33n2/1678-4464-csp-33-02-e00173315.pdf. Acesso em 23 de janeiro de 2019.

OLIVEIRA, LRC. Antropologia e moralidade. 1993.

http://www.anpocs.org.br/portal/publicacoes/rb cs_00_24/rbcs24_07.htm (acesso em 08/Mai/ 2015). Apud BARBIERI; CLA; COUTO, MT; AITH, FMA. A (não) vacinação infantil entre a cultura e a lei: os significados atribuídos por casais de camadas médias de São Paulo, Brasil. Cad. Saúde Pública 2017; 33(2): e00173315. Disponível em: http://www.scielo.br/pdf/csp/v33n2/1678-4464-csp-33-02-e00173315.pdf. Acesso em 23 de janeiro de 2019.

ORGANIZAÇÃO das Nações Unidas no Brasil. OMS alerta sobre epidemia de sarampo [Internet]. Organização das Nações Unidas; 2014. Disponível em: https://nacoesunidas.org/omsalertasobre-epidemia-de-sarampo/ Apud Moura, ADA; Carneiro, AKB; Braga, AVL; et al. Estratégias e resultados da vacinação no enfrentamento da epidemia de sarampo no estado do Ceará, 2013-2015 Epidemiol. Serv. Saúde, Brasília, 27(1):e201634310, 2018. Disponível em: https://scielosp.org/pdf/ress/2018.v27n1/e201634310. Acesso em 23 de janeiro de 2019.

ORTELLADO Pablo: Brasil esteve na 'vanguarda' das fakenews. Veja, São Paulo, 11 de mai. 2018. Disponível em: https://veja.abril.com.br/tveja/em-pauta/pablo-ortellado-brasil-estevenavanguarda-das-fake-news/. Acesso em 23 de janeiro de 2019.

PAIM JS. Desafios para a saúde coletiva no século XXI. Salvador: EDUFBA; 2006. Apud SOUSA, IV; BRASIL, CCP; SILVA, RM; et al. Diagnóstico participativo para identificação de problemas de saúde em comunidade em situação de vulnerabilidade social. Ciência \& Saúde Coletiva, 22(12):3945-3954, p.3949, 2017. Disponível em:

http://www.scielo.br/pdf/csc/v22n12/1413-8123-csc-22-12-3945.pdf. Acesso em 23 de janeiro de 2019. 
PINHEIRO, L.V.R. Redes e sistemas de informação: interação e integração. [Rio de Janeiro: s. n.]. Trabalho encomendado pela Biblioteca Nacional, 1995. Apud CONDURÚ, M.T. e PEREIRA, J.A.R. Gestão da informação em saneamento básico no Estado do Pará sob o enfoque do ciclo informacional. EngSanitAmbient | v.22 n.6 | nov/dez 2017 | 1225-1232. Disponível em: http://www.scielo.br/pdf/esa/v22n6/1809-4457-esa-22-06-1225.pdf. Acesso em 23 de janeiro de 2019.

PSAFE Tecnologia S.A. DFNDR Lab. RELATÓRIO da segurança digital no Brasil: segundo trimestre - 2018. Rio de Janeiro, 2018. Disponível em: https://www.psafe.com/dfndr-lab/wpcontent/uploads/2018/08/dfndr-lab-Relat\%C3\%B3rio-da-Seguran\%C3\%A7a-Digital-no-Brasil2\%C2\%BA-trimestre-de-2018.pdf. Acesso em 23 de janeiro de 2019.

RAULIN, O; DURAND, G; GILLET, Y; BES, M; LINA, G; VANDENESCH, F; et al. ToxinprofilingofStaphylococcusaureusstrainsinvolved in varicellasuperinfection. $J$ ClinMicrobiol. 2010;48: 1696-700. Apud HIROSE, M; GILIO, AE; FERRONATO, AE. et al. Impacto da vacina varicela nas taxas de internações relacionadas à varicela: revisão de dados mundiais. Rev Paul Pediatr. 2016;34(3):359---366. Disponível em: http://www.scielo.br/pdf/rpp/v34n3/pt_0103-0582-rpp-34-03-0359.pdf. Acesso em 23 de janeiro de 2019.

ROSSI, Amanda. Empresas que permitem disseminação de fakenews devem ser multadas, diz um dos principais teóricos sobre a relação entre política e tecnologia. BBC News Brasil em São Paulo. 3 novembro 2018. Disponível em: https://www.bbc.com/portuguese/geral-46067403. Acesso em 23 de janeiro de 2019.

SANCHES, D. Doenças erradicadas podem voltar por falta de vacinação. O Estado de S.Paulo, São Paulo, Publicado em 20/06/2018. Disponível em: https://emais.estadao.com.br/noticias/comportamento, doencas-erradicadas-podem-voltar-porfalta-de-vacinacao,70002357899. Acesso em 23 de janeiro de 2019.

SATO, APS; FERREIRA, VLR; TAUIL, MC; RODRIGUES, LC; BARROS, MB; MARTINELI, E; et al. Uso de registro informatizado de imunização na vigilância de eventos adversos pós-vacina. RevSaude Publica. 2018;52:4. Disponível em: http://www.scielo.br/pdf/rsp/v52/pt_0034-8910-rsp-S1518-87872018052000295.pdf. Acesso em 23 de janeiro de 2019.

SEGATO, RL. Antropologia e direitos humanos: alteridade e ética no movimento de expansão dos direitos universais. Mana 2006; 12:207-36. Apud BARBIERI; CLA; COUTO, MT; AITH, FMA. A (não) vacinação infantil entre a cultura e a lei: os significados atribuídos por casais de camadas médias de São Paulo, Brasil. Cad. Saúde Pública 2017; 33(2): e00173315. Disponível em: http://www.scielo.br/pdf/csp/v33n2/1678-4464-csp-33-02-e00173315.pdf. Acesso em 23 de janeiro de 2019.

SILVA, FS; Barbosa, YC; Batalha, MA; et al. Incompletude vacinal infantil de vacinas novas e antigas e fatores associados: coorte de nascimento BRISA, São Luís, Maranhão, Nordeste do Brasil. Cad. Saúde Pública 2018; 34(3):e00041717. Disponível em: https://scielosp.org/pdf/csp/2018.v34n3/e00041717. Acesso em 23 de janeiro de 2019. 
SOCIEDADE Goiana de Pediatria. Movimento antivacinas pode trazer doenças erradicadas de volta. Publicado em 12/07/2018. Disponível em:

http://www.sbp.com.br/filiada/goias/noticias/noticia/nid/movimento-antivacinas-pode-trazerdoencas-erradicadas-de-volta/. Acesso em 23 de janeiro de 2019.

SOUSA, IV; BRASIL, CCP; SILVA, RM; et al. Diagnóstico participativo para identificação de problemas de saúde em comunidade em situação de vulnerabilidade social. Ciência \& Saúde Coletiva, 22(12):3945-3954, 2017. Disponível em: http://www.scielo.br/pdf/csc/v22n12/14138123-csc-22-12-3945.pdf. Acesso em 23 de janeiro de 2019.

WAKSMAN, RD; HIRSCHHEIMER, MR (coordenadores) Manual de atendimento às crianças e adolescentes vítimas de violência. Brasília: Conselho Federal de Medicina/Sociedade de Pediatria de São Paulo; 2011. Disponível em:

https://portal.cfm.org.br/images/stories/biblioteca/manual\%20atendimento\%20crianca\%20adoles cente.pdf. Acesso em 23 de janeiro de 2019.

WORLD Health Organization (WHO).Carta de Ottawa. In: Brasil. Ministério da Saúde (MS), Fiocruz. Promoção da saúde: Cartas de Ottawa, Adelaide, Sundsvall e Santa Fé de Bogotá. Brasília: MS, IEC; 1986. Apud SOUSA, IV; BRASIL, CCP; SILVA, RM; et al. Diagnóstico participativo para identificação de problemas de saúde em comunidade em situação de vulnerabilidade social. Ciência \& Saúde Coletiva, 22(12):3945-3954, 2017. Disponível em: http://www.scielo.br/pdf/csc/v22n12/1413-8123-csc-22-12-3945.pdf. Acesso em 23 de janeiro de 2019.

ZIEBOLD, C; VON KRIES, R; LANG, R; WEIGL, J; SCHMITT, HJ.Severecomplicationsofvaricella in previouslyhealthychildren in Germany: a 1-year survey. Pediatrics. 2001;108:e79. Apud HIROSE, M; GILIO, AE; FERRONATO, AE. et al. Impacto da vacina varicela nas taxas de internações relacionadas à varicela: revisão de dados mundiais. Rev Paul Pediatr. 2016;34(3):359---366. Disponível em:

http://www.scielo.br/pdf/rpp/v34n3/pt_0103-0582-rpp-34-03-0359.pdf. Acesso em 23 de janeiro de 2019. 